\title{
LIÇÕES DE COISAS E ENSINO DAS CIÊNCIAS NA FRANÇA NO FIM DO SÉCULO 19: CONTRIBUIÇÃO A UMA HISTÓRIA DA CULTURA
}

\author{
Pierre Kahn \\ Université de Caen Basse-Normandie, França.
}

\section{Resumo}

Além das grandes reformas realizadas na organização institucional da escola primária, gratuidade, obrigação, laicidade, os republicanos franceses do final do século 19 quiseram operar uma profunda transformação dos conteúdos de ensino e das normas pedagógicas. As ciências experimentais foram imensamente beneficiadas com isso e se tornaram, em 1882, uma disciplina regular da escola primária com os seus programas e a sua carga horária. A lição de coisas, procedimento pedagógico pelo qual os reformadores se entusiasmaram desde 1860, ficará estreita e naturalmente associada a esse ensino. Ela é, inicialmente, de fato, uma lição de observação: onde os alunos encontrarão melhores oportunidades para observar do que nas aulas de história natural ou de física elementar? Assim, ligados entre si, o ensino das ciências e a lição de coisas têm dois aspectos, um prosaico, outro encantador. Contexto prosaico: o ensino das ciências, destinado a alunos que, na sua maioria, não conhecerão outra escola a não ser a primária, deve permanecer prático e usual. A lição de coisas convém especialmente a esse ensino porque ela trata primordialmente das realidades concretas e familiares. Contexto encantador: o ensino das ciências é um instrumento poderoso de educação intelectual, até mesmo de educação moral e política. Ele representa a esperança de uma educação liberal primária tão completa, digna e válida em seu gênero, quanto às humanidades clássicas do secundário. A lição de coisas, ao fazer corresponder a abordagem pedagógica ao próprio método da ciência, o método indutivo, se torna então, por excelência, o que permite esta educação intelectual. Esta tensão não é própria ao ensino das ciências. Essa análise enseja, antes de mais nada, evidenciar o duplo discurso que os republicanos tiveram sobre uma escola que eles transformaram, simultaneamente, em realidade e sonho.

Palavras-chave: atividade (do aluno), escola primária, educação intelectual, educação prática, ensino concreto, ensino das ciências, lição de coisas, método indutivo, método intuitivo, observação, pedagogia. 


\section{OBJECT LESSONS AND SCIENCE EDUCATION IN FRANCE IN THE LATE NINETEENTH CENTURY: CONTRIBUTION TO A HISTORY OF THE SCHOOL CULTURE}

\section{Abstract}

Apart from the major reforms carried out in the institutional organization of primary school (gratuity, obligation, secularism), the French Republicans in the late nineteenth century were willing to make a profound transformation of educational content and teaching standards. Experimental sciences have benefited greatly in 1882 and become a regular discipline of primary school, its programs and its time distribution. The lesson, teaching method which reformers were raving since the $1860 \mathrm{~s}$, will be closely and naturally associated with this teaching. It is indeed a first observation lesson or where students find they best opportunities to observe that in natural history lessons or basic physics? And related to each other, and science education and object lesson has two sides, one prosaic, another enchanted. Versant prosaic science education, for students who, for the most part, do not know of another school that the primary must be practical and conventional . If the lesson is particularly suitable for this teaching is that it focuses on concrete and familiar realities. Versant enchanted science education is a powerful instrument intellectual education (even moral and political education). It embodies the hope of a primary liberal education as complete, valid and worthy of its kind that classical humanities school. The lesson, matching the pedagogical approach to the same method of science (inductive method) becomes by allowing this intellectual education. This tension is not unique to science education. Analysis allows rather highlighting the double discourse that Republicans held on a school they simultaneously turned into reality and dream.

Keywords: activity (student), elementary school, intellectual education, education practice, concrete education, science education, object lesson, inductive method, intuitive method, observation, pedagogy.

\section{LECCIONES PRÁCTICAS Y ENSEÑANZA DE LAS CIENCIAS EN FRANCIA A FINALES DEL SIGLO 19: CONTRIBUCIÓN A UNA HISTORIA DE LA CULTURA ESCOLAR}

\section{Resumen}

Además de las importantes reformas llevadas a cabo en la organización institucional de la escuela primaria (gratuito, obligación, secularismo), a finales del siglo 19, los franceses republicanos estaban dispuestos a hacer una profunda transformación de los contenidos y de las normas pedagógicas. Ciencias experimentales han beneficiado en gran medida en 1882 y convertido en una disciplina regular de la escuela primaria, sus programas y su distribución en el tiempo. La Lección de las cosas, método de enseñanza que los reformistas estaban entusiasmados, desde la década de 1860, será destrecha y de forma natural asociado a esta enseñanza. De hecho, es una primera lección de observación o donde los estudiantes se mejores oportunidades de observar que en las clases de historia natural o física básica? Y en relación con la otra, y la lección educación científica tiene dos caras, una prosaica, otro "encantado". La educación científica prosaico, para los estudiantes que, en su mayor parte, no saben de otra escuela que el principal debe ser práctico y convencional. Si la lección es particularmente adecuada para esta enseñanza es que se centra en las realidades concretas y conocidas. En contexto encantador, la enseñanza és un poderoso instrumento de educación intelectual (incluso la educación moral y política). Encarna la esperanza de una "educación liberal" primaria completa, válida y digna de su tipo que las humanidades clásicas escuela. La lección de las cosas, que coincide con el enfoque pedagógico con el mismo método de la ciencia (método inductivo) se convierte en la excelencia, al permitir este tipo de educación intelectual. Esta tensión no es aplicable sólo a la educación científica. La análisis de este estudio permite, ante todo, poner de relieve el doble discurso que los republicanos celebraron en una escuela a la que al mismo tiempo se convirtieron en realidad y el sueño.

Palabras-clave: actividad (estudiantes), escuela primaria, educación intelectual, educación práctica, enseñanza concreta, enseñanza de las ciencias, lección de las cosas, método inductivo, método intuitivo, observación, pedagogía. 


\title{
LEÇONS DE CHOSES ET ENSEIGNEMENT DES SCIENCES EN FRANCE \\ A LA FIN DU 19E SIECLE: CONTRIBUTION A UNE HISTOIRE DE LA CULTURE SCOLAIRE
}

\begin{abstract}
Résumé
Outre les grandes réformes accomplies dans l'organisation institutionnelle de l'école primaire (gratuité, obligation, laïcité), les républicains français de la fin du $19 \mathrm{e}$ siècle ont eu la volonté d'opérer une profonde transformation des contenus d'enseignement et des normes pédagogiques. Les sciences expérimentales en ont fortement bénéficié et deviennent en 1882 une discipline régulière de l'école primaire, avec ses programmes et sa répartition horaire. La leçon de choses, procédé pédagogique pour lequel les réformateurs s'enthousiasment depuis les années 1860, va être étroitement et naturellement associée à cet enseignement. Elle est en effet d'abord une leçon d'observation; or, où les élèves trouveront-ils meilleures occasions d'observer qu'au cours de leçons d'histoire naturelle ou de physique élémentaire? Ainsi liés l'un à l'autre, enseignement des sciences et leçon de choses ont deux versants, l'un prosaïque, l'autre enchanté. Versant prosaïque: l'enseignement des sciences, destiné à des élèves qui, pour la plupart, ne connaîtront pas d'autre école que le primaire, doit rester pratique et usuel. Si la leçon de choses convient particulièrement à cet enseignement, c'est qu'elle porte avant tout sur des réalités concrètes et familières. Versant enchanté: l'enseignement des sciences est un instrument puissant d'éducation intellectuelle (voire d'éducation morale et politique). II incarne l'espoir d'une éducation libérale primaire aussi complète, digne et valable en son genre que les humanités classiques du secondaire. La leçon de choses, en faisant correspondre la démarche pédagogique à la méthode même de la science (la méthode inductive) devient alors par excellence ce qui permet cette éducation intellectuelle. Cette tension n'est pas propre à l'enseignement des sciences. L'analyse de celui-ci permet bien plutôt de mettre en évidence le double discours que les républicains ont tenu sur une école qu'ils ont simultanément transformé en réalité et en rêve.

Mots-clé: activité (de l'élève), ecole primaire, education intellectuelle, education pratique, enseignement concret, enseignement des sciences, leçon de choses, méthode inductive, méthode intuitive, observation, pédagogie.
\end{abstract}




\section{Introdução}

$\mathrm{N}$ a história escolar da França, a lei de 28 de março de 1882 ficou famosa: foi ela que estabeleceu a instrução obrigatória, para os dois sexos de 6 a 13 anos, e a laicidade dos ensinos. Antes disso, em 1881, havia sido estabelecida a gratuidade total da escola primária. Mas ela se distingue também pelo fato de ter integrado as Ciências Físicas e Naturais no currículo primário corrente. Pequena coisa em uma grande lei? Não acreditamos nisso. Ela mostra, pelo contrário, que as reformas iniciadas não foram somente estruturais, relacionadas à organização institucional da escola: laicidade, gratuidade, obrigação, etc. Elas diziam respeito também ao currículo e quiseram propor uma renovação, tanto da cultura escolar, quanto da pedagogia. É o que testemunha, por um lado, a revalorização do ensino científico primário, e por outro, o esforço de renovação pedagógica que se inscreve na promoção do método das lições de coisas: dois aspectos do processo reformador articulados estreitamente entre si, na medida em que o ensino científico vai constituir um ponto de implantação privilegiado para justificar o valor pedagógico das lições de coisas.

\section{O advento das ciências na escola da Terceira República: o sentido complexo de um reconhecimento}

Quando as Ciências Físicas e Naturais, em 1882, se tornaram um ensino regular do currículo primário, não foram as únicas beneficiadas por tal promoção. Pela Lei Falloux, de 1850, as matérias escolares estavam divididas em duas categorias: obrigatórias e facultativas. As matérias obrigatórias não eram numerosas: educação moral e instrução religiosa, leitura, elementos da língua francesa e do cálculo, ao que Victor Duruy acrescentou, em 1867, história e geografia da França. Quanto às facultativas, além das ciências, havia desenho, trabalhos manuais, música ou ainda ginástica. Essas matérias não tinham um programa - portanto, não havia manuais - tão pouco lugar previsto no calendário e os professores não eram formados para ensiná-las, o diploma simples para professor compreendia somente as matérias obrigatórias. Compreende-se, então, que qualificar estes ensinos de facultativos era, realmente, designá-los como supérfluos e colocá-los às margens da instrução pública. É o que confessa, aliás sem dissimulação, Hippolyte Fortoul, ministro da Instrução Pública de Louis-Napoléon Bonaparte, em 1854:

O objetivo do ensino primário é proporcionar a todas as crianças os primeiros instrumentos indispensáveis ao desenvolvimento da sua inteligência. É necessário excluir o luxo, procurando a utilidade prática. $O$ esforço de introduzir nas pequenas escolas algumas das matérias que pertencem às escolas secundárias nos levaria a um engano total. A lei de 15 de março de 1850 circunscreveu sabiamente esse ensino, tornando-o mais sólido, o que em aparência perderia em extensão. Estaríamos nos expondo ao debilitar, enfraquecer mesmo a instrução primária se, como fizemos seguidamente, condenássemos à discussão de sutilezas gramaticais crianças que mal sabem ler e escrever, se obrigássemos a assistir às aulas de física e de história natural quando elas nem mesmo conhecem as bases de aritmética. Faça, Senhor Reitor, que toda criança, segura, aliás, por suas convicções cristãs que devem ser a regra da vida, saia da escola primária sabendo ler, escrever e contar, e o Senhor terá todo o mérito do país. (Fortoul, in Gréard, 1893, p. 613) 
Não poderíamos dizer mais claramente que é tão indispensável limitar o ensino primário quanto libertá-lo ${ }^{1}$, e apreciaremos particularmente o destino das ciências que Fortoul - com a reforma da bifurcação foi o incentivador de uma revalorização do ensino científico nos liceus - reconhece pertencer naturalmente ao secundário e que ele faz, portanto, passar para o primário, em forma de aprovação, do facultativo ao inútil.

Contrastando, a escola da Terceira República aparece como tomada por uma vontade notável de reavaliação do ensino primário. Certamente, essa vontade não era sem precedente. O final do Segundo Império, no ministério de Victor Duruy, já tinha testemunhado um esforço real para engrandecer, aprofundar e renovar a cultura e a pedagogia primárias, insistindo no interesse das matérias facultativas ${ }^{2}$ e integrando a História e a Geografia nas matérias obrigatórias. Mas Duruy, finalmente, não tocou no princípio que distingue as matérias obrigatórias e facultativas e deixou as ciências junto a essas últimas. A obra escolar de Jules Ferry e dos seus colaboradores marcou, portanto, muito bem uma virada decisiva a este respeito. As Ciências Físicas e Naturais, como as demais matérias até então facultativas, têm agora um programa, horários, uma progressão definida do curso elementar ao superior.

Elas fazem parte de pleno direito dos conhecimentos que, segundo os termos famosos de Octave Gréard, ninguém pode alegar o desconhecimento da lei. Pressupõese que concorram plenamente à formação do homem e do cidadão, com um currículo primário profundamente revalorizado, cujos responsáveis republicanos não hesitam em escrever que ele provém, ele também, como o secundário, da educação liberal ${ }^{3}$ e que abrange ensinamentos com denominações e conteúdos inéditos na escola primária, até então reservados aos liceus, como é o caso dos elementos de Direito e de Economia Política, as noções de literatura ou, ainda, a Matemática.

O lugar das Ciências no novo currículo também permanece ambíguo e esta ambiguidade remete àquela que, de uma maneira mais global, continua a afetar geralmente a cultura primária: cultura reavaliada a ponto de parecer a Jules Ferry como o despertar de um novo regime para a escola ${ }^{4}$, mas ao mesmo tempo restrita aos limites de uma instrução popular que permanece social e intelectualmente separada do secundário.

\footnotetext{
${ }^{1}$ Este minimalismo escolar resulta diretamente do medo provocado junto às classes dirigentes pela insurreição dos trabalhadores em junho de 1848. A escola primária e os professores foram julgados responsáveis. Trata-se, então, de protegê-los das excitações de uma falsa ciência (Beugnot, Relatório sobre o projeto de lei apresentado pelo conde de Falloux, ministro da Instrução Pública, feito em nome da comissão parlamentar encarregada de examinar o projeto. Sessão de 6 de outubro de 1849. In: GREARD, Octave. 1875, p. 214) e de impedir a desclassificação das crianças do povo; uma instrução demasiadamente abrangente riscaria de levar à ilusão uma ambição social desmedida.

2 Ver, por exemplo, GASQUIN. Sur l'enseignement des matières facultatives: les conférences faites à la Sorbonne aux instituteurs primaires venus à Paris pour l'exposition universelle de 1867. Paris: Hachette, 1868.

${ }^{3}$ Ver, por exemplo, Jules Ferry: "Todos estes acessórios (as lições de coisas, a história e a geografia, o ensino do desenho, as noções de história natural, os museus escolares, a ginástica, os passeios escolares, os trabalhos manuais, os corais), todos esses acessórios [...] são, segundo nossa visão, primordiais porque neles reside a virtude educativa, porque os acessórios farão da escola primária uma escola de educação liberal." Discurso pronunciado no Congresso Pedagógico dos Professores, 19 de abril de 1881. In: ROBIQUET, Paul. Discours et opinions de Jules Ferry. Paris: Armand Colin, 1893-1898, tome 4, p. 250.

${ }^{4}$ FERRY, Jules. Discours au congrès pédagogiques des instituteurs, 19 avril 1881. In: ROBIQUET, Paul. Discours et opinions de Jules Ferry. Paris: Armand Colin, 1893-1898, tome 4, p. 250.
} 
O ensino das Ciências testemunha, exemplarmente, esta hesitação e podemos distinguir no seu contexto três tipos de discursos diferentes, até mesmo opostos ${ }^{5}$.

\section{O modelo utilitarista}

Segundo um primeiro tipo, que chamaremos utilitarista, as Ciências devem, essencialmente, manter a dimensão utilitária e prática que é tradicionalmente a da escola primária, para deixar a cultura teórica para o secundário. Assim, o verbete Química do Dictionnaire de pédagogie et d'instruction primaire ${ }^{6}$, redigido pelo professor de Química Jean-Pierre Liès-Bodart, insistira sobre a necessidade, na escola primária, de restringir as Ciências nos limites das suas utilizações práticas: "evitaremos as abstrações e as teorias científicas, as grandes hipóteses explicativas [...] o detalhe das questões muito contraditórias ou complicadas" (Liès-Bodart, in Buisson, 1882-87, p. 377).

O naturalista Edmond Perrier adotou uma opinião igual no artigo História Natural, do mesmo dicionário, no ensino primário:

Devido, em geral, ao pouco tempo disponível à obrigação de condensar em um ensino de poucos anos tudo o que é indispensável conhecer da vida cotidiana [...], não se pode esperar reunir um número suficiente de fatos para que possam fornecer uma base bastante sólida às idéias gerais. (Perrier, in Buisson, 1882-87, p. 1274)

Tal é também a opinião do inspetor geral Augustin Boutan, no relatório entregue a Jules Ferry sobre o ensino das Ciências Físicas e Naturais nas escolas normais de formação de professores:

No ensino secundário, o objetivo principal é a cultura intelectual, no seu sentido mais amplo. Pelo estudo da física, especialmente, ensinamos aos alunos o que é realmente o método experimental [...]. O lado filosófico da questão tem aqui uma importância primordial [...]. No ensino primário, o objetivo a ser atingido, e, em seguida, os meios a serem empregados são bem diferentes [...]. O aluno-professor não entenderá nada sobre estas sínteses ousadas, sobre estas generalizações científicas que convêm aos alunos mais adiantados dos nossos liceus. É preciso colocá-lo imediatamente em presença dos fenômenos da natureza que ele observou mal, é verdade, mas que lhe será ensinado a melhor conhecer. [...]. Caso tratar-se das leis da natureza, limitar-nos-emos a formular as mais importantes [...]. Seguirão as aplicações usuais oriundas dos princípios precedentemente formulados. As aplicações na agricultura e na indústria local despertarão um grande interesse nos alunos-professores e servirão de ponto de partida para o futuro professor. Inclusive nas escolas normais primárias, a formação deve ter um objetivo mais imediato, mais prático. (Boutan, 1880, p. 29)

\footnotetext{
${ }^{5}$ Ver KAHN, Pierre. Les sciences, trois modèles pour un enseignement nouveau. In: DENIS, Daniel; KAHN, Pierre (éds.). L'Ecole républicaine et la question des savoirs: enquête au cœur du Dictionnaire de pédagogie de Ferdinand Buisson. Paris: CNRS, 2003.

6 Elaborado e dirigido por Ferdinand Buisson, o poderoso diretor do ensino primário (nomeado para este cargo, em 1879, permanecerá ali até 1896), o Dictionnaire de pédagogie do qual participam mais de 300 colaboradores constitui um observatório privilegiado das concepções educativas e, não unânimes, da França do início da Terceira República.
} 
Aqui se atribui, claramente, uma finalidade mais utilitária do que educativa ao ensino das Ciências e isso vai moderar sensivelmente o entusiasmo de Jules Ferry ao falar de um novo regime para a escola. Esse entusiasmo, em todo caso, não leva os responsáveis pela Terceira República a romper com o que era, desde a Lei Guizot de 1833, o destino geral dos estudos primários, voltados para os usos da vida, nem a pôr em causa a separação entre o primário, escola do povo, que a maioria dos alunos abandonará aos treze anos para seguir a vida ativa, e o secundário, escola das elites:

[O ensino primário] não perde jamais de vista que as escolas primárias não têm tempo para perder com discussões inúteis, com teorias científicas, com curiosidades escolásticas, e que não é demais passar cinco a seis anos na escola para muni-los com um pequeno tesouro de ideias das quais terão estritamente necessidade para poder conservá-las e aumentálas posteriormente. (Organisation pédagogique, 1882, p. 16)

A instrução científica primária, em suma, teria que se conformar com esta regra geral. Assim, onde a lei de 1882 menciona os elementos de Ciências Naturais, Físicas e Matemática, os programas que a seguem indicam que esses elementos são usuais e fazem desaparecer a referência à Matemática, disciplina propriamente secundária. As Ciências estão, aliás, muito longe de figurarem no currículo formal como ensino preponderante e isso pode ser confirmado pela simples leitura da carga horária destinada a cada matéria: nos programas de 1882 elas só ocupam os alunos, dependendo dos níveis do curso, duas horas por semana, ao passo que, quando a Aritmética era ensinada uma hora por dia e a Língua Francesa - leitura, escrita, ditado e gramática - quatro horas por dia.

\section{O modelo educativo}

As ciências experimentais foram introduzidas no ensino primário bem mais pelo seu valor educativo do que pelos resultados imediatos que possam dar, aumentando a bagagem dos alunos com alguns conhecimentos úteis ou com alguns segredos da indústria. (Haraucourt, in Buisson 1882-87, p. 2369)

Esta declaração de Célestin Haraucourt, professor de Física no Liceu de Rouen, é manifestamente exagerada: acabamos de ver quanto a administração escolar, ao contrário, se aplicava em manter o ensino das Ciências nos limites das suas aplicações práticas e das suas utilizações usuais. Ela mostra, entretanto, a existência de outro tipo de discurso contrabalançando com o primeiro, que realmente não ficou isolado, incluindo, neste caso, os responsáveis pela instrução pública e, segundo o qual o ensino científico primário se justifica não somente pela sua utilidade, mas também, e principalmente, pela educação intelectual à qual ele contribui intensamente.

O tema de uma ciência educadora, para retomar uma expressão que o químico Marcellin Berthelot intitulou uma das suas obras, e não somente utilitária, é amplamente tratado. Numerosas obras e autores estão de acordo com as declarações de Elie Pécaut, médico higienista e filho desta grande figura da escola republicana francesa que foi Félix Pécaut, publicadas em um artigo da Revue pédagogique: 
Sem dúvida, poucos são os elementos destas ciências que o professor deve ensinar aos seus alunos. Mas não devemos nos enganar sobre isso. Independentemente da sua utilidade e do seu valor próprio, para os alunos, essas noções sumárias, reduzidas ao mínimo indispensável, têm ainda outro valor, elas visam outro objeto, que é o de servir eficazmente às finalidades da educação. É ali que se encontra, para dizer a verdade, o seu destino capital. Elas não são, e não devem ser, nas mãos do professor, senão o instrumento de uma cultura superior. Através delas, é necessário que ele faça uma obra educativa. E que obra! Excetuando-se a cultura moral, não há nada mais árduo nem mais considerável. Com a ajuda destes rudimentos de ciência [...], é necessário que ele encontre um meio para despertar a alma infantil à revelação da ordem na natureza, à criação das leis que a regem; que ele a impregne de respeito pelos seus preceitos, de admiração pela sua harmonia, de curiosidade pelos seus mistérios; que ele a domine cedo para esta disciplina forte e salutar, feita de observação atenta, de análise penetrante, de investigação, ao mesmo tempo ousada e prudente; que ele inculque nela, para sempre, esta fé imperturbável na estabilidade da ordem natural que é a única que a tornará inacessível às superstições de qualquer tipo, e, com isso, fará uma alma verdadeiramente livre. Se fosse apenas o fato de enriquecer a criança com alguns conhecimentos úteis [...], de the ensinar, por exemplo, a aperfeiçoar os adubos [...], sim, estaríamos de acordo, a tarefa seria humilde, e não seria preciso tanta preparação para isso. Mas, na verdade, isso representa a mínima das coisas; este saber prático, tão útil que possa parecer, não é, porém, senão o mínimo dos dons que a cultura científica confere à criança. O dom realmente precioso, inestimável entre todos, é de suscitar nela este espírito de livre exame que é a alma do pensamento moderno em todos os seus modos, sem o qual ela estaria um tanto fora do seu tempo, como uma estranha entre nós, e que o chamamos espírito científico. (Pécaut, 1883, p. 482)

O ensino das Ciências seria, então, educativo por ser uma formação do espírito científico, próprio para libertar das superstições, ainda vivas numa França dominantemente rural, e para desenvolver o espírito crítico, este espírito de livre exame. Mas esse ensino engloba também formação moral, porque submete [a alma] bem cedo a esta disciplina forte e salutar, exigida pela abordagem científica, e que ensina, ao mesmo tempo, a coragem de pensar e a prudência, até mesmo a modéstia, na busca ou na comunicação da verdade, investigação ao mesmo tempo árdua e prudente.

Ocorre mesmo que, às vezes, seja enfatizado não somente o alcance moral da educação científica, mas igualmente o seu alcance político. Testemunho disso é esta passagem de Paul Bert, fisiologista de renome e eminente responsável republicano - ele foi deputado e Ministro da Instrução Pública entre dois ministérios Ferry:

Quando ele tiver aprendido com o estudo das ciências naturais e físicas o culto da lei, quando ele souber cientificamente que todo o efeito tem uma causa antecedente, não tenham mais medo que este capricho tirado da natureza, o aluno ao se tornar homem e cidadão o admitirá na sociedade; que ele abandone o seu direito, consequência da lei, para se entregar nas mãos da graça. Não, quando ele não acreditar mais nos milagres, ele não esperará mais nada dos golpes de estado. $E$, de fato, o que é o milagre senão um golpe de estado na natureza? O que é um golpe de estado, senão um milagre na sociedade? (Bert, 1881, p. 401) 
Aqui, as aulas de Ciências se tornam lições de instrução cívica republicana: elas contribuem a não acreditar mais nos milagres dos golpes de Estado e nos homens providenciais - o golpe de Estado de Louis-Napoléon Bonaparte que, em dezembro de 1851, derrubou a Segunda República é evidentemente visado. O ensino científico primário é, então, erigido por Paul Bert em verdadeiro paradigma educativo da escola primária: as Ciências são para os pequenos do primário. Elas são as humanidades da escola primária, como as línguas antigas, o Latim e o Grego, são as humanidades do secundário:

Não é por entusiasmo profissional que eu atribuo às ciências físicas e naturais um papel preponderante no ensino e principalmente no ensino primário. Certamente, é indispensável conhecer as regras da gramática e os fatos principais da história, mas as razões das regras gramaticais são muito abstratas para penetrar no espírito das crianças; quanto à história, quem ousará dizer que o aluno das escolas primárias pode ali captar o encadeamento filosófico dos fatos? É completamente diferente para as ciências naturais que aguçam os sentidos, criando um hábito de ver certo e de tudo ver [...], e, para as ciências físicas que, além da observação, chamam à sua ajuda a experimentação, e acostumam assim a não acreditar em nada sem que a prova siga imediatamente a afirmação [...]. As ciências podem sozinhas ensinar a incredulidade sem ensinar o cepticismo, este suicídio da razão. (Bert, 1882, p. 3)

Paul Bert é a ilustração exemplar de um cientificismo republicano, mas não o único no fim do século 19 na França. Marcellin Berthelot também foi outro exemplo notável que não se contentou apenas em insistir sobre o valor educativo do ensino científico, mas chegou ao ponto de fazer disso o emblema de um novo projeto cultural que a Terceira República quis ou pretendeu promover.

Certamente este novo projeto, tal como apresentado por Paul Bert, foi uma maneira de sonhar com o ensino científico primário, bem mais do que uma descrição da sua realidade, que, segundo vimos, era bem mais prosaica. Os numerosos responsáveis republicanos que afirmaram, eles também, o interesse educativo - e não somente utilitário - do ensino das Ciências chegaram mesmo a dizer ou acreditar que ele ocupava o centro que Paul Bert lhe conferia idealmente. É verdade que este sonho foi realmente sonhado. Ele faz parte das representações que acompanharam a elaboração de um ensino científico regular na escola primária: representações que a história dos desafios culturais e sociais do ensino não poderia negligenciar.

\section{O modelo crítico}

Existiu, no início da Terceira República, um terceiro tipo de discurso sobre o ensino científico primário, que propomos chamá-lo crítico, porque minora o alcance de tal ensino, partilhando com os demais que, ao contrário, tendem a majorar a recusa de ver na referência aos usos práticos a finalidade primordial da instrução primária.

Em outros termos, este tipo de discurso deseja, ele também, uma revalorização da cultura primária no sentido de que, até então, a educação liberal se referia unicamente ao secundário; com isso, adere inteiramente ao projeto - ao sonho? - reformador de um novo regime para a escola primária que Jules Ferry declarava querer criar, fazendo dos ensinamentos tradicionalmente acessórios, os ensinamentos principais por serem 
verdadeiramente educativos. Mas ele recusava às Ciências a capacidade de ser o elemento portador de tal projeto. Na escola primária, o educativo devia primar sobre o utilitário, certamente, mas as Ciências permaneceram no campo do ensino utilitário e as novas finalidades culturais esperadas para o primário foram, então, transferidas às matérias como a poesia ou a música, próprias para elevar a alma da criança.

Essa é, notadamente, a posição expressa por Félix Pécaut nos verbetes Música e Poesia do Dictionnaire de pédagogie. Pécaut (1882-87) distingue, assim, em Poesia dois gêneros de disciplinas ensinadas na escola primária: as matérias de simples instrução, puramente instrumentais, das quais as Ciências fazem exemplarmente parte, e as matérias de educação geral, entre as quais ele inclui a moral, a religião, mas também a educação poética, própria para servir de contrapeso espiritual a uma cultura científica positiva espontaneamente orientada para a ação e as preocupações práticas:

A ciência vê as coisas de outra maneira; ela estuda, ao mesmo tempo, o seu aspecto exterior e as suas condições de existência; ela decompõe, mede, pesa, recompõe enquanto que a poesia vê com uma única olhada direta e de conjunto [...], com um olhar sintético, a ciência vê analiticamente. Diferentes são os hábitos de espírito dados pela cultura poética, o convívio assíduo com a poesia, diferente daqueles dados pela cultura científica. Mas ambas são necessárias à saúde espiritual. Estamos realmente de acordo que o homem, levado a considerar as coisas da natureza, da história, da humanidade, unicamente pelo seu lado poético, seria impróprio à ação e se sentiria como um estranho perdido na vida. É verdade também que a ação, a ciência, a $\operatorname{arte}^{7}$, têm apenas uma importância medíocre, não atingem um grau mais elevado, são tomadas por uma impotência secreta, com um tipo de dificuldade de ser e de viver, se a poesia não os estimular interiormente pela sua chama; à curiosidade comum ou às melhores ambições práticas, elas não associam este sentimento da maravilha das coisas, da maravilha nos seres, no seu destino, no universo [...]. Caso este sentimento se enfraquecer ou se apagar em um povo [...] toda atividade perderá a sua grandeza; a perfeição dos métodos, o poder dos mecanismos intelectuais, a preparação para a vida [...] bastará algum tempo para dissimular a decadência; mas o rio que ainda corre sob os nossos olhos está seco ou a sua fonte está empobrecida. (Pécaut, in Buisson, 1882-87, p. 2388)

Contrariamente aos desejos de Paul Bert, não é, portanto, às Ciências nem à formação intelectual positiva que elas permitem constituir o fundo da cultura primária e o equivalente, em sua ordem, das humanidades clássicas do secundário. É necessário bem mais que isso para Félix Pécaut propor um contrapeso espiritual no sentido prático que formam as ciências positivas, sentido prático e indispensável, mas incapaz sozinho de satisfazer as aspirações mais elevadas do espírito. Félix Pécaut e Paul Bert sonham com uma escola primária prometida enfim às humanidades e à educação liberal. Mas o sonho espiritualista de um, não tem o mesmo conteúdo do sonho cientificista do outro.

Esta diferença é importante. Porém, ela não deve mascarar o que os discursos de Paul Bert e de Félix Pécaut testemunham em comum: tendo como projeto a reforma da escola, a Terceira República duplicou a realidade das prescrições - circulares, planos de estudo, etc. - com uma dimensão imaginária, que o ensino das Ciências, sem dúvida, por

\footnotetext{
${ }^{7}$ No sentido de técnica.
} Hist. Educ. [Online] 
ser uma novidade, pouco pôde contribuir a alimentar. Mesmo desagradando a Paul Bert e Jules Ferry, as Ciências não representaram, na realidade, uma matéria preponderante, nem a atividade educadora principal da escola - e contrariando Félix Pécaut, a poesia foi menos ainda. Mas em torno delas se construiu um discurso ideológico original, que determinou a significação e a tendência a erigi-las na vitrine de um projeto cultural ambicioso e inédito. Projetou-se, então, sobre a escola, um complexo de representações em que a idéia do ensino científico se articulou com alguns dos grandes temas de um discurso impregnado de cientificismo - Progresso, Razão, Luzes, Moral da ciência - e com o sonho educacionista da Terceira República.

O ensino científico primário tem, em suma, na escola republicana que surge, uma dupla existência: uma existência real, diurna, se assim podemos dizer, determinada pelos programas e suas orientações pedagógicas, codificada pelos manuais, que se desenvolve a uma distância respeitável das esperanças, dos sonhos filosóficos da República e lembra pelo seu intitulado oficial - elementos usuais de ciências físicas e naturais - a modéstia dos seus objetivos e a sua fidelidade com uma orientação prática da escola primária que já era aquela da lei Guizot, em 1833, e uma existência sonhada, noturna, manifestada nos grandes discursos políticos sobre a escola, os engajamentos filosóficos dos atores, as proclamações militantes sobre a nova importância e grandeza das finalidades da educação científica.

\section{As figuras indecisas da lição de coisas}

A idealização, objeto do ensino científico primário no início da escola republicana francesa, teve a sua originalidade e justificativa pedagógica: o entusiasmo pelas lições de coisas, preciosidade da renovação pedagógica que os republicanos desejam ardentemente e cujas virtudes vão especialmente se impregnar no ensino das Ciências. A história da instrução científica primária vai, então, duravelmente até aos anos 1960, confundir-se com a história das lições de coisas, e essas aparecerão para gerações de escolares como o outro nome das lições de ciências. Mas a lição de coisas foi também apresentada como um modelo pedagógico geral e, neste sentido, não particularmente ligado a um conteúdo de ensino especial. Assim, entre pedagogia geral e didática das ciências, as figuras da lição de coisas são plurais e um pouco imprecisas.

\section{Lição de coisas e método intuitivo: uma vontade de renovação pedagógica}

A pedagogia francesa não aguardou a Terceira República, nem Jules Ferry para vangloriar os méritos da lição de coisas. Desde os anos 1860 esses foram reconhecidos e proclamados por uma administração escolar preocupada em renovar os métodos de ensino, atendendo uma maior exigência da atividade do aluno. Começa a se construir uma crítica severa de um ensino escolástico: o adjetivo é então empregado em um sentido claramente pejorativo, livresco, privilegiando a memória bem mais do que a inteligência, saber de cor bem mais do que compreender. Os renovadores vêem esta atividade do aluno garantida por dois princípios.

O princípio intuitivo: a criança conhece somente o que ela pode, inicialmente, ver, tocar, sentir. A intuição sensível é a sua primeira relação com o mundo que à cerca. A observação é o ponto de partida de todos os seus conhecimentos: 
A criança nasce com o gosto de observar e de conhecer. A vida interior ainda não despertou nela, ela pertence inteiramente aos fenômenos do mundo que a cerca: todos os seus sentidos estão despertos; todos os objetos que o seu olhar ou que a sua mão encontram a atraem, a interessam, a encantam. (Gréard, 1875, p. 70) ${ }^{8}$

Trata-se aqui do que chamamos, há muito tempo na Alemanha, o método intuitivo, sendo a lição de coisas, em suma, a ilustração exemplar. O método lição de coisas consiste em colocar a criança em presença direta com o seu meio, isto é, o contrário da lição de palavras recebida pelo aluno. Trata-se, assim, de uma convicção comum, lembrada, como exemplo, veemente pelo inspetor Charles Defodon:

$\mathrm{Na}$ maioria dos casos, como procedemos? Apresentamos às crianças palavras, palavras que são representações das nossas idéias, das nossas próprias idéias, lógico. E sem pensarmos se essas palavras têm para elas o mesmo significado que para nós, nós nos contentamos em lhes dar as palavras [...]. O que resulta, enfim, para 40 alunos entre 100, é a estatística que o diz, dessas lições tão laboriosamente dadas, por um lado, tão penosamente aceitas, por outro? Os alunos realmente nada aprenderam ou se contentam com palavras vãs. (Defodon, 1868, p. 318.)

O princípio indutivo: a indução segue logicamente a intuição: após ter observado as realidades concretas que os cercam, os alunos poderão, progressivamente, passar às idéias mais gerais que essas realidades expressam. Proceder do concreto ao abstrato, dos fatos às ideias, do simples ao complexo, tais são as formulações comuns e equivalentes do credo pedagógico de todos os responsáveis pela instrução pública desde 1860. Na Inspection des écoles primaires, os inspetores Eugène Brouard e Charles Defodon são adeptos incondicionais:

O método recomendado à atenção inteligente dos professores é aquele que, partindo de verdades conhecidas, de fatos sensíveis, de imagens ou exemplos colocados sob os olhos das crianças, remonta gradualmente às verdades que queremos que conheçam, aos princípios cujos fatos particulares são a consequência, às regras cujos exemplos dados não representam senão a aplicação. (Brouard; Defodon, 1874, p. 115)

Jules Ferry não inventa, portanto, nada quando, em 1881, no Primeiro Congresso Nacional de Professores, exalta que

estes novos métodos que consistem em não ditar mais como um decreto a regra à criança, mas em fazê-la encontrá-la; que se propõem, preferencialmente, incentivar e despertar a espontaneidade do aluno, dirigindo o desenvolvimento normal ao invés de prendê-lo nas regras prontas que ele não compreende nada, ao invés de limitá-lo em fórmulas das quais ele não extrai senão o tédio e que só conseguem lançar nestas cabecinhas ideias vagas e pesadas, como uma espécie de crepúsculo intelectual. (Ferry, 1895, p. 520)

\footnotetext{
${ }^{8}$ Octave Gréard foi diretor do ensino primário do Departamento de la Seine. Assim que se tornou ministro, em 1879, Jules Ferry o nomeou vice-reitor da Académie de Paris. 
Mas ele sublinha a que ponto estes novos métodos são a garantia da atividade. Ferry fala, inclusive, de espontaneidade da criança e do quanto, desde então, a lição de coisas contribui para isso - o que já dizia, há uns quinze anos antes, Marie PapeCarpantier, propagadora das lições de coisas, desejando vê-las sair das salas de asilos, ancestrais das escolas maternais, onde elas nasceram, para integrarem o ensino primário:

Mas quem, então, faz o valor das lições de coisas? A que se deve que sejam tão reputadas, tão recomendadas e efetivamente tão produtivas? Ah! Senhores, isso se deve a uma grande lei, extremamente desconhecida, que não quer que haja paciente em educação; que deseja que o aluno seja um agente ativo, tão ativo quanto o professor; que ele seja seu colaborador inteligente nas lições que ele recebe, e que, segundo a expressão do catecismo, ele coopere com a graça! (Marie Pape-Carpantier, 1868, p. 17)

Resumindo, o ensino primário deve ser intuitivo, indutivo e ativo. É o que proclamam, aliás, oficialmente e nestes termos, as instruções de 1887. Podemos assim dizer que, com o movimento iniciado em 1860 e seguido pelos responsáveis republicanos, o discurso pedagógico institucional entrou na modernidade.

\section{As lições de coisas: lições de tudo ou lições de ciências?}

Esta maneira de abordar e de defender as lições de coisas parece, entretanto, comportar uma consequência: inscrevendo a lição de coisas no registro das novas verdades da pedagogia moderna, os renovadores the conferem um valor e um alcance gerais. Marie Pape-Carpantier escreve, explicitamente, que a lição de coisas é uma lição de tudo: "É preciso lembrar, inicialmente, que a lição de coisas não é uma área especial de ensino, mas uma forma que se adapta a todos os níveis de assuntos, aos mais elevados e aos mais complexos, como aos mais simples e aos mais fáceis" (Marie PapeCarpantier, 1868, p. 22).

Como se apresenta, então, a relação entre as lições de coisas e o ensino das Ciências? Esse não é senão uma aplicação particular delas? Segundo uma expressão atribuída a Jules Ferry, a lição de coisas é a base de tudo? Deveria assim existir lições de coisas em História, em Aritmética, em Gramática, bem como no campo das Ciências Naturais? A resposta é não. Com a inclusão das Ciências nas matérias regulares da escola primária, em 1882, a lição de coisas vai progressivamente se centralizar nesta disciplina; ela vai se disciplinarizar. A lição de coisas vai se tornar não mais a expressão exemplar e geral do método intuitivo, mas uma aplicação deste método a uma categoria especial de realidades: os objetos naturais de ordem sensível. Ou seja, a lição de coisas se torna o prefácio e o prelúdio de todos os estudos experimentais, o exercício de iniciação às Ciências Físicas, à Geografia, à História Natural, enfim, a todos os conhecimentos que têm relação aos sentidos e que devem ser observados pelos sentidos (Platrier, in Buisson, 1882-87).

Pode parecer normal de ver assim a lição de coisas encontrar no ensino científico primário seu lugar de predileção, pois ela preconiza partir com os alunos para observar o mundo exterior, pois as Ciências Naturais são precisamente ciências de observação. Podemos até pensar que a afirmação do valor pedagógico das lições de coisas não 
representou nada no reconhecimento do ensino das Ciências na escola primária: paradoxalmente um procedimento tão recomendado não conseguiu, ou conseguiu mal, ser exercido em uma matéria na qual, aparentemente, poderia se desenvolver na sua plenitude. Nada impede que esta nova centralização disciplinar nas Ciências corresponda a uma evolução do discurso pedagógico sobre a lição de coisas. Ela não deve ser uma lição de tudo. Sobre isso, o filósofo e especialista em história da pedagogia Gabriel Compayré escreveu: "o campo das ciências está necessariamente reduzido às ciências [...]. Delas é preciso indiscutivelmente excluir a história, a gramática, as ciências abstratas, como a aritmética e todas as ciências morais" (Compayré, 1885, p. 295).

Marie Pape-Carpantier não tem, portanto, razão. Ela foi criticada explicitamente pelo diretor da Escola Normal Narcisse Platrier:

É preciso reconhecer que Pape-Carpantier deu à expressão lições de coisas uma extensão que ultrapassa a medida certa. A lição de coisas é, para ela, uma espécie de procedimento enciclopédico que the permite ensinar todas as outras matérias do programa, incluso a língua e a moral. (Platrier, 1882-87, p. 1529)

Mesmo assim, os discursos permanecem instáveis e equívocos e os responsáveis republicanos pela instrução pública não desistem completamente de apresentar as lições de coisas como o remédio universal contra as aberrações conduzidas por um ensino demasiadamente livresco. Nós já mencionamos o parecer de Ferry fazendo da lição de coisas a base de tudo. Já em 1894 o ministro Léon Bourgeois continuava a fazer da lição de coisas o meio para evitar os absurdos das provas para o certificado primário de estudos em História (Bourgeois, 1987, p. 232). Entre lição de tudo e lição de ciências, entre pedagogia geral e procedimento apropriado a uma matéria de ensino, a lição de coisas tem dificuldade para achar uma identidade clara, mesmo se a tendência é indiscutivelmente à sua centralização disciplinar no ensino científico.

\section{A lição de coisas entre sonho e realidade}

Confundida cada vez mais, embora nem sempre inteiramente, com o ensino das Ciências, a lição de coisas abarcou todas as ambiguidades, ora vangloriada como o procedimento que melhor convém a um ensino das Ciências modesto, concreto e extremamente utilitário, ora privilegiada por ser a pedagogia que melhor se adapta às novas ambições de uma formação intelectual autêntica e elevada.

\section{Lição de coisas e ensino usual das ciências: a primazia do concreto}

Já vimos que a insistência, às vezes colocada na finalidade utilitária do ensino primário das Ciências, conduziu muitos responsáveis republicanos ou pedagogos em insistir sobre a necessidade de não sobrecarregar a mente dos alunos da escola primária com abstrações e sutilezas teóricas reservadas a outro tipo de ensino, o secundário. Deste ponto de vista, a lição de coisas aparece como a forma pedagógica ideal para os pequenos alunos primários: ela tem por definição realidades concretas. O seu caráter intuitivo a preserva justamente dos perigos do ensino abstrato e verbal. Assim, quanto mais jovem for o aluno, tanto maior será o seu valor, pois a sua inteligência ainda não 
está desperta. Ela pode inclusive ser particularmente recomendada para alunos atrasados ${ }^{9}$.

Em suma, a lição de coisas é um método que, por seu caráter concreto e por tratar o meio imediato dos alunos, convém naturalmente a um ensino limitado em suas ambições intelectuais. E essa maneira de associá-la ao ensino científico primário salienta, então, o que esse ensino tem de usual, de prático, de independente das finalidades educativas mais elevadas do ensino secundário.

\section{Uma formação do espírito científico?}

Será que na dupla polaridade em função da qual se construiu a legitimidade do ensino primário das Ciências, o pólo utilitário versus o pólo educativo, a lição de coisas faz a balança pender para o lado utilitário? Não necessariamente, pois existe outra maneira de fazer da lição de coisas o método exigido para a instrução científica das crianças do povo: insistindo não sobre a sua justificação utilitária, mas justamente sobre a justificação educativa. Em que efetivamente o ensino das Ciências pode ser educativo? Todos aqueles que, na época, salientavam esta finalidade afirmam: formando o espírito. Mas de que modo ele possui esta aptidão formadora? Aqui também a resposta é unânime: essa aptidão se deve ao fato que os alunos, com as Ciências, não aprendem somente resultados, mas também, e principalmente, um método, um modo de raciocínio, uma maneira de pensar. É precisamente este espírito de exame, do qual falava Elié Pécaut, ou ainda esta disposição para não acreditar mais nos milagres, que Paul Bert esperava que ela libertasse os alunos de todas as superstições, mesmo as políticas ${ }^{10}$.

Mas qual é então o método científico? A unanimidade predomina sempre para responder: o método indutivo. Ora, o método indutivo é o próprio método das lições de coisas: partir do concreto para se elevar às verdades mais gerais, proceder do concreto para atingir o abstrato. Em outros termos, a ordem pedagógica preconizada corresponde à ordem epistemológica suposta, e é justamente nisso que a lição de coisas pode esperar corresponder às ambições educativas primordiais. É este ponto de vista que se afirma, por exemplo, no texto Lição de coisas do Dictionnaire de pédagogie, no qual o autor retoma, por sua conta, o comentário do filósofo inglês Alexander Bain, dizendo que "o estudo qualitativo dos sons (lições de coisas) devia permitir remontar até as leis as mais abstratas da acústica" (Platrier, in Buisson, 1882-87, p. 1534). E se tal é o valor do método intuitivo comum à Ciência e às lições de coisas, através das quais nós ensinamos, nada impede que a lição de coisas seja o ponto de partida de um ensino científico que vai até o secundário:

O método é geral. Ele não se aplica somente às escolas primárias. As escolas normais, os colégios, os liceus devem importar dele seus procedimentos e conservá-los até o final dos estudos com as modificações que os meios exigem. As ciências físicas e naturais não serão jamais bem ensinadas se as lições não considerarem os objetos e as experiências concernentes. (Platrier, in Buisson, 1882-87, p. 1534)

\footnotetext{
${ }^{9}$ Ver KAHN, Pierre. La leçon de choses: eléments pour une archéologie des savoirs scolaires. Penser l'éducation, 2000, n. 8, p. 81-115.

10 Sobre este tema ver, também, LIARD, Louis. La science et l'esprit scientifique. In: Pour les instituteurs, conférences d'auteuil, 1906. Paris: Delagrave, 1907. 
A dupla justificativa, prosaica e ideal, do ensino científico primário corresponde, assim, a uma dupla justificativa da lição de coisas. Versão prosaica: a ênfase dada ao caráter concreto das lições de coisas é uma maneira de sublinhar os limites fora dos quais o ensino científico primário, que deve permanecer usual, não deve se aventurar. Versão idealizada: praticando as lições de coisas, o professor forma jovens espíritos voltados à observação atenta e metódica do mundo e, procedendo assim, os inicia à própria ciência. Ele não ensina ciência rudimentar, mas ciência elementar, pois se a observação não representa o todo da abordagem científica, ela é o ponto de partida e, formando os alunos na disciplina que requer, por mais simples e concretas que forem suas aulas, o professor já está na ciência, em uma atividade que é também aquela do cientista ${ }^{11}$. Não causa surpresa ao ver Paul Bert, um dos adeptos dos mais eloquentes da concepção educacionista do ensino primário das Ciências, defender esta concepção educativa e quase epistemológica da lição de coisas:

Quando você mostrar a uma criancinha objetos pretos, brancos, vermelhos, verdes, e que você lhe pedir para dar o nome destas cores, você já não está the ensinando elementos de ciências naturais? [...] Quando você pegar um espelho e que receber sobre a sua superfície um raio de sol, se você mostrá-lo à criança explicando [...] que fazendo oscilar o espelho, ele faz oscilar o ponto luminoso e que ela pode mexê-lo à vontade sobre a parede ou fazer com que os seus colegas pisquem os olhos, quando você lhe ensinar que existe uma ligação entre a maneira de colocar o espelho e a maneira com que se faz movimentar o ponto luminoso; o que isso representa senão a física? Porque você lhe ensinou nada mais do que as leis da reflexão da luz. Quando você colocar no fundo de um copo cheio de vinagre duas pedrinhas, sendo que uma fica intacta e a outra deixa escapar gases que sobem à superfície do líquido fazendo pequenas bolhas, para a alegria das crianças, elas ficam encantadas com isso; querem saber porque essas pedras aparentemente iguais, se comportam no líquido de maneira tão diferente. O que é isso, senão química, esta química horrível tão pouco compreendida, mesmo dos nossos alunos secundaristas. (Bert, 1881, p. 396)

\section{Conclusão}

Conclui-se insistindo sobre a ambivalência das significações tomadas, no momento da criação da escola republicana francesa, no final do século 19, pelo ensino das Ciências e o método das lições de coisas que Ihe foi sustentavelmente associado. Este ensino consegue, então, ser admitido de pleno direito no currículo primário, justificando-se duplamente, e como em tensão, pela sua finalidade utilitária, tradicionalmente designada à escola primária, desde o início do século 19, e pela sua finalidade cultural, que pretende ser, quanto a ela, mais inédita e é elogiada como tal. Do mesmo modo, as lições de coisas se articulam com este ensino, ora se apresentando como a pedagogia concreta

\footnotetext{
${ }^{11}$ É o que já escrevia Condorcet, autor emblemático, no momento da Revolução Francesa, sobre um projeto de instrução pública no qual a posteridade republicana pretendia ver a inspiração originária das suas reformas escolares: "os elementos são uma verdadeira parte da ciência, restringida em estreitos limites, mas completa por si só" (Rapport et décret sur l'organisation générale de l'instruction publique (1792). In: Ecrits sur l'instruction publique. Paris: Edilig, 1989, segundo volume, p. 103-104).
} 
que convém ao seu destino utilitário, ora como o método capaz de trazer as ambições do novo projeto educativo, o novo regime escolar do qual se valia Jules Ferry.

Esta tensão é exemplar por ser considerada como analisadora das ambiguidades constitutivas do projeto escolar republicano, tomado entre o desejo, o sonho democrático de elevar a cultura popular, de até mesmo construí-la como cultura de pleno direito, e a preocupação conservadora de manter a separação entre uma escola primária limitada a um ensino orientado para os usos da vida e um secundário desejoso da cultura desinteressada, que oferece às elites sociais que o frequentam. Uma história da cultura escolar desta época deve comportar as duas pontas desta cadeia: não alimentar ingenuamente a lenda de uma escola primária meritocrática, naturalmente aberta para os seus melhores alunos, para os estudos prolongados do liceu e, mais tarde, da universidade. Aconteceu bem mais a exceção do que a regra, mas, ao mesmo tempo, reconhecer que os próprios fundadores da escola republicana contribuíram à origem desta lenda, mantendo sobre o seu trabalho escolar um discurso encantador.

\section{Referências}

BERT, Paul. L'Instruction dans une démocratie. In: BERT, Paul. Discours et conférences. Paris: G. Charpentier, 1881.

BERT, Paul. La Deuxième année d'enseignement scientifique. Paris: Armand Colin, 1882.

BOURGEOIS, Léon. Discours au XIlle congrès de la ligue de l'enseignement. In: GAUTHIER, Guy; NICOLET, Claude. La laïcité en mémoire. Paris: Edilig, 1987, p. 232.

BOUTAN, Augustin. Rapport de la commission d'enquête des sciences physiques et naturelles. Paris: Imprimerie nationale, 1880.

BROUARD, Eugène; DEFODON, Charles. Inspection des écoles primaires. Paris: Hachette, 1874.

BUISSON, Ferdinand (dir.). Dictionnaire de pédagogie et d'instruction primaire. Paris: Hachette, 1882-87.

COMPAYRE, Gabriel. Cours de pédagogie théorique et pratique. Paris: P. Delaplane, 1885.

DEFODON, Charles. La méthode de l'enseignement par les yeux, Manuel général de l'instruction primaire, Partie spéciale, 17 octobre 1868, n. 42, p. 318.

FERRY, Jules. Discours au congrès pédagogique des directeurs et directrices d'école normale et des inspecteurs primaires, 2 avril 1880. In: ROBIQUET, Paul. Discours et opinions de Jules Ferry, tome 3. Paris: Armand Colin, 1895, p. 520-521.

FORTOUL, Hippolyte. Circulaire aux Recteurs du 31 octobre 1854. In: GRÉARD, Octave. Législation de l'instruction primaire en France depuis 1789 jusqu'à nos jours. Paris: Delalain Frères, 1893, tome 3, p. 613.

GREARD, Octave. L'Enseignement primaire à Paris et dans les communes du département de la Seine en 1875. Paris: Charles de Mourgues Frères, 1875.

GREARD, Octave. Législation de l'instruction primaire en France depuis 1789 jusqu'à nos jours, tome 3. Paris: Delalain Frères, 1893.

HARAUCOURT, Célestin. Article Physique. In: BUISSON, Ferdinand (dir.). Dictionnaire de pédagogie et d'instruction primaire. Paris: Hachette, 1882-87. 
KAHN, Pierre. De l'enseignement des sciences à l'école primaire: l'influence du positivisme. Paris: Hatier, 1999.

KAHN, Pierre. La leçon de choses: eléments pour une archéologie des savoirs scolaires. Penser l'éducation, n. 8, 2000, p. 81-115.

KAHN, Pierre. La leçon de choses: naissance de l'enseignement des sciences à l'école primaire. Villeneuve d'Ascq: Septentrion, 2002.

KAHN, Pierre. Les sciences, trois modèles pour un enseignement nouveau. In: DENIS, Daniel; KAHN, Pierre (éds.). L'Ecole républicaine et la question des savoirs: enquête au cœur du Dictionnaire de pédagogie de Ferdinand Buisson. Paris: CNRS, 2003.

LELIEVRE, Claude. Jules Ferry: la république éducatrice. Paris: Hachette, 1999.

LIARD, Louis. La science et l'esprit scientifique. In: Pour les instituteurs, conférences d'auteuil, 1906. Paris: Delagrave, 1907.

LES CONFERENCES faites à la Sorbonne aux instituteurs primaires venus à Paris pour l'Exposition universelle de 1867. Paris, Hachette, 1868.

LIES-BODART, Jean-Pierre. Article Chimie. In: BUISSON, Ferdinand (dir.). Dictionnaire de pédagogie et d'instruction primaire. Paris: Hachette, 1882-87, p. 377.

LOEFFEL, Laurence. Ferdinand Buisson: apôtre de l'école laïque. Paris: Hachette, 1999.

ORGANISATION PEDAGOGIQUE et plan d'études des écoles primaires publiques de 1882. Paris: Delalain Frères, 1882, p. 16.

PAPE-CARPANTIER, Marie. Conférences sur l'introduction de la méthode des salles d'asile dans l'enseignement primaire. Paris: Hachette, 1868.

PECAUT, Elie. Quelques mots au sujet de l'enseignement des sciences physiques et naturelles à l'école normale primaire. Revue pédagogique, n. 6, 1883, p. 482-484.

PECAUT, Félix. Article Poésie. In: BUISSON, Ferdinand (dir.). Dictionnaire de pédagogie et d'instruction primaire. Paris: Hachette, 1882-87.

PERRIER, Edmond. Article Histoire naturelle. In: BUISSON, Ferdinand (dir.). Dictionnaire de pédagogie et d'instruction primaire. Paris: Hachette, 1882-87, p. 1274.

PLATRIER, Narcisse. Article Leçons de choses. In: BUISSON, Ferdinand (dir.). Dictionnaire de pédagogie et d'instruction primaire. Paris: Hachette, 1882-87.

PROST, Antoine. Histoire de l'enseignement en France 1800-1967. Paris: A. Colin, 1968.

ROBIQUET, Paul. Discours et opinions de Jules Ferry. Paris: Armand Colin, 1893-1898.

PIERRE KAHN é professor universitário em Ciências da Educação, da Ecole Supérieure du Professorat e da Educação da Universidade de Caen BasseNormandie, diretor adjunto do Centre d'Etudes et de recherches en Sciences de l'Education, Cerse, responsável pelo Cerse de l'axe Histoire, Institutions, Disciplines, Idées, Acteurs (Hidia), membro fundador do Comitê científico da coleção Enseignement et réformes da editora Presses Universitaires de Grenoble, secretário da Association Transdisciplinaire pour les Recherches sur l'Histoire de I'Education - Atrhe. 
Endereço: Département des Sciences de l'Éducation - Université de Caen BasseNormandie - CS 14032 - Caen - Cedex 5 - France

E-mail: kahnpi@wanadoo.fr.

Recebido em 10 de agosto de 2013.

Aceito em 3 de dezembro de 2013. 